\title{
Ecological Engineering Cropping Methods for Enhancing Predator, Cyrtorhinus lividipennis (Reuter) and Suppression of Planthopper, Nilaparvata lugens (Stal) in Rice- Effect of Border Cropping Systems
}

\author{
K. Chandrasekar ${ }^{1 *}$, N. Muthukrishnan ${ }^{1}$ and R.P. Soundararajan ${ }^{2}$ \\ ${ }^{1}$ Department of Agricultural Entomology, Tamil Nadu Agricultural University, \\ Coimbatore, Tamil Nadu, India \\ ${ }^{2}$ Department of Rice, Tamil Nadu Agricultural University, Coimbatore, Tamil Nadu, India \\ *Corresponding author
}

A B S T R A C T

Three aroma and non-aroma crops were raised separately as border crops in and around rice field (var. CO 51) to enhance the activity of predatory mirid bug, Cyrtorhinus

Keywords

Ecological engineering, Pest management, Nonrice crop, Border cropping system, $N$. lugens,

C. lividipennis, Olfactometer.

Article Info

Accepted:

04 October 2017

Available Online:

10 December 2017 lividipennis (Reuter) and to mitigate brown planthopper (BPH) Nilaparvata lugens (Stal). The aroma varieties viz., Pusa Basmati-1, Pusa Suganth and Jeeraga Samba, the non-aroma varieties viz., BPT 5204, ADT 36 and ADT 43 were used as border crops. Laboratory experiments were also conducted to study the orientation of $C$. lividipennis towards different leaf and flower sample of border crops through eight-armed olfactometer. Result revealed that mean field population of mirid bugs and $\mathrm{BPH}$ on rice crop varied from 3.24 to 7.24 and 1.88 to 4.82 per hill in the border cropped system. Rice + Pusa Basmati border cropping system significantly enhanced the population of $C$. lividipennis on rice (7.24/hill) along with highest occurrence ratio (1.16) with more CB ratio (1:1.50). This was followed by Rice + Pusa Suganth, Rice + Jeeraga Samba and Rice + BPT 5204 border cropping systems (6.97, 6.70 and 4.78 mirid bugs/hill on rice) respectively. Rice + ADT 43 border cropping system however recorded with less population of mirid bug (3.84 per hill on rice) and in rice alone had the population of 3.22 per hill. Similarly, populations of mirid bugs on border crops ranged from 2.18 to 8.38 per hill. Maximum mirid bug population (8.38/plant) was observed on Rice + Pusa Basmati border crop. Pusa Suganth and Jeeraga Samba registered 8.06 and 7.31 mirid bugs per plant respectively. This study concluded that Rice + Pusa Basmati and Rice + Pusa Suganth can be used as border crops in rice ecosystem to enhance the availability of mirid bugs. In olfactometer studies, mirid bug attraction was higher towards Pusa Basmati leaf (3.00) and flower (3.56) samples.

\section{Introduction}

Insect pest infestation is one of the major biotic stress in rice cultivation and from sowing to maturity stage it causes various levels of damage and resulting in lower productivity. Out of many insect species, 100 species attack rice while rests are considered as friendly insects. Almost 20 insects are considered as rice pests of economic importance that include stem borers, gall midge, defoliators and vectors like leafhoppers and planthoppers that cause direct damage and transmit various diseases (Pathak 1970). The stem borer, brown planthopper $(\mathrm{BPH})$, gall midge and leafhopper are among 
important pests in Southeast Asia and China while gall midge, BPH and yellow stem borer accounted for major yield loss in South Asia (Sardesai, 2001). Damages caused by insects disturb physiology of plants and resulted in to lower crop yield (Nasiruddin and Roy, 2012). These conditions have lead to growing interest in recent times in the conservation of existing entomophages in rice cropping systems with enhanced biological attributes through conservation biological control (CBC). CBC was defined as the modification of the environment or existing practices to protect and enhance specific natural enemies of other organisms to reduce the effect of pests (Eilenberg et al., 2001). Recently ecological engineering methods emerged as a paradigm for considering pest management approaches that are based on cultural practices and informed by ecological knowledge rather than on high technology approaches such as synthetic pesticides and genetically engineered crops (Gurr et al., 2004a). Ecological engineering is a relatively new concept of environmental manipulation for the benefit of man and the environment. These methods are best tools to conserve, enhance natural enemy population and increase their availability in the field. Ecological engineering pest management methods include use of cultural practices, usually based on vegetation management, to enhance biological control or the 'bottom-up' effects that act directly on pests (Gurr et al., 2004b). The latter include methods such as trap crops, intercrops and maintaining certain weed strips along with main crop availability (Altieri and Schmidt, 1986; Thies and Tscharntke, 1999).

\section{Materials and Methods}

\section{Study site and experimental design}

The present investigation was conducted at Krish Vigyan Kendra (KVK),
Needamangalam, Thiruvarur district, Tamil Nadu, India during November to January, 2015. The experiment was laid out in Randomized Block Design with seven treatments and three replications. The field plot size was $6 \times 4 \mathrm{~m}^{2}$.

Twenty days old seedlings of var. CO-51 from the nursery were transplanted in the main field at spacing of $20 \times 20 \mathrm{~cm}$. Aroma varieties such as Pusa Basmati-1, Pusa Suganth and Jeeraga Samba; and non-aroma rice varieties viz., BPT 5204, ADT 36 and ADT 43 were raised as a border crop (two rows) around main rice crop.

Normal agronomic practices like fertilizer application, manual weeding was carried out as per the crop production recommendation. No chemical pesticides were given throughout the season. For border crops, all rice crops were sown / planted at that time of transplanting (Table 1).

\section{Effects of aroma rice on mirid bug and BPH population}

\section{Field experiments}

Ten plants were selected randomly from each treatments and in situ count was taken during early morning hours at weekly intervals. In rice, total number of mirid bugs was observed from bottom of hills and was expressed as numbers/ hill. Observations were also taken in all the border crops at the same period of time.

\section{Occurrence ratio}

Similarly, by using in situ counts, occurrence ratio (OR) of predators and parasitoids as the case may be on aroma and non-aroma border crops, was estimated by using following formula of Muthukrishnan and Dhanasekaran (2014). 
$\mathrm{OR}=$ Population of natural enemies on aroma and non-aroma border crops / Occurrence of natural enemies on rice crop

\section{Cost: Benefit Ratio (CBR)}

Cost: Benefit Ratios were worked out for all the field experiments, using the formula of Akila Selvaraj and Sundara Babu (1994).

$\mathrm{CB}$ Ratio $=$ Cost of produce $/$ Cost of cultivation + Cost of plant protection

\section{Olfactometer studies}

Olfactometer studies were conducted at Department of Agricultural Entomology, TNAU, Coimbatore using Complete Randomized Design (CRD). Ten grams of healthy plant leaves were kept in the arm and were firmly closed with a lid. The inlet of the olfactometer on the top center place was connected to an aquarium pump (220-240 volt Ac) to release the pressure. Out of eight arms, leaf samples were kept in six arms and two arms were treated as control. Medical air was passed from aquarium pump at the rate of 4 lit/min into the olfactometer. Twenty numbers of mirid bugs (male and female) were released to the olfactometer through a central hole which also served as odour exit hole. Observations were made on the number of predators settled on each arms at 5, 10, 15 and 20 MAR (Minutes After Release) for their host preference. This experiment was replicated four times. Using similar methodology, this experiment was conducted for different flower samples.

\section{Statistical analysis}

The data were collected from all the experiments and mean values were calculated. Numerical values were transformed into square root transformations before subjecting them to statistical analysis (Gomez and
Gomez, 1984). Means in RBD analysis were separated by Least Significant Difference test (DMRT).

\section{Results and Discussion}

\section{Field studies}

The results of field study on impact of border crops on the incidence of BPH and mirid bug revealed that there was significant variation on different border cropping systems. Mean population of $N$. lugens was 4.82 /tiller on pure rice crop (Table 2) when raised without any border crops. Minimum population of $N$. lugens was observed in rice + Pusa Basmati-1 (1.88/tiller). This was followed by rice + Pusa Suganth (2.04/ tiller) and rice + Jeeraga Samba (2.27/ tiller). The higher plant hopper population on rice was observed in rice + BPT 5204 (2.75/tiller), rice + ADT 36 (3.27/ tiller) and rice + ADT 43(3.42/ tiller).

Mean population of mirid bugs were significantly more $(7.24 /$ hill) in rice based border cropping system than rice alone (3.22/hill). Rice border cropped with Pusa Basmati-1 recorded the highest number of mirid bugs (7.24/hill) on rice plants. This was followed by rice + Pusa Suganth (6.97/hill) and rice + Jeeraga Samba (6.70/hill). However rice + BPT 5204, rice + ADT 36 and rice + ADT 36 border cropping systems registered lesser populations of mirid bugs (4.78, 4.47 and 3.87/hill).

Pusa Basmati-1 border crop had the highest population of mirid bugs (8.38) followed by Pusa Suganth (8.06) and Jeeraga Samba (7.31). However border crops viz., BPT 5204 (3.64/hill), ADT 36 (3.09/hill) and ADT 43 (2.18/hill) had the least population. Border crops viz., Pusa Basmati-1, Pusa Suganth, Jeeraga Samba, BPT 5204, ADT 36 and ADT 43 registered occurrence ratio of $1.16,1.16$, $1.09,0.76,0.69$ and 0.57 for mirid bug 
respectively. Pusa Basmati- 1 as border crop had more number of mirid bug population might be due to abundance of pollen and nectar compared to other border crops. In Pusa Basmati-1 border cropping system, the population of $C$. lividipennis was $6.07,6.80$ and 6.40 at 36, 43 and 50 DAT. After 57 DAT, there was reduction in the population of C. lividipennis (Fig. 1).

Generally, trap crops and intercrops are plant stands grown to attract organisms like predators and parasitoids to protect target crops from pest attack. Bund cropping of okra, mungbean and string bean were expected that, increase in structural diversity lead to increase in predatory abundance, particularly spider population to achieve more benefits under the situations of unwarranted excessive use of insecticides and sole reliance on intensive chemical management (Uetz, 1991).

The definition of trap cropping focuses on the interactions between the plant and the pest rather than on the natural enemies of the insect pest. We chose this delineation to preserve the distinction between habitat manipulation for enhanced biological control and the various examples of what we suggest constitute trap cropping. However, in addition to diverting insect pests away from the main crop, trap crops can also reduce insect pest populations by enhancing populations of natural enemies within the field. For example, Pusa basmati 1 trap crop used to manage yellow stem borer, Scirpophaga incertulas W. (Kumar et al., 2013).

Fig.1 Influence of border crops on $N$. lugens and Cyrtorhinus lividipennis population

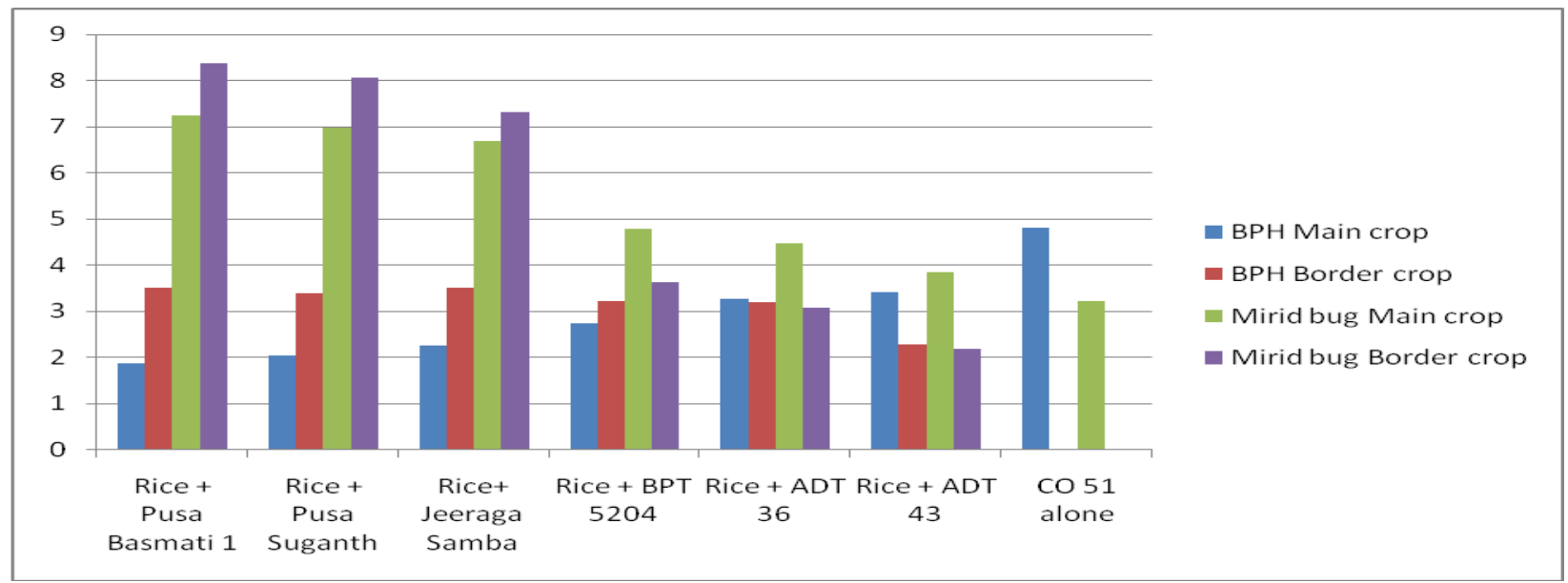

Table.1 Crop varieties and time of sowing

\begin{tabular}{|l|l|l|}
\hline S.No & \multicolumn{1}{|c|}{ Variety name } & \multicolumn{1}{c|}{ Time of Planting } \\
\hline $\mathbf{1}$ & Pusa Basmati 1 & At the time of main plant transplanting \\
\hline $\mathbf{2}$ & Pusa Suganth & At the time of main plant transplanting \\
\hline $\mathbf{3}$ & Jeeraga Samba & At the time of main plant transplanting \\
\hline $\mathbf{4}$ & BPT 5204 & At the time of main plant transplanting \\
\hline $\mathbf{5}$ & ADT 36 & At the time of main plant transplanting \\
\hline $\mathbf{6}$ & ADT 43 & At the time of main plant transplanting \\
\hline $\mathbf{7}$ & CO 51 (main crop) & At the time of main plant transplanting \\
\hline
\end{tabular}


Table.2 Effect of Aroma and non-Aroma as border cropping systems on population of Cyrtorhinus lividipennis and Nilaparvata lugens

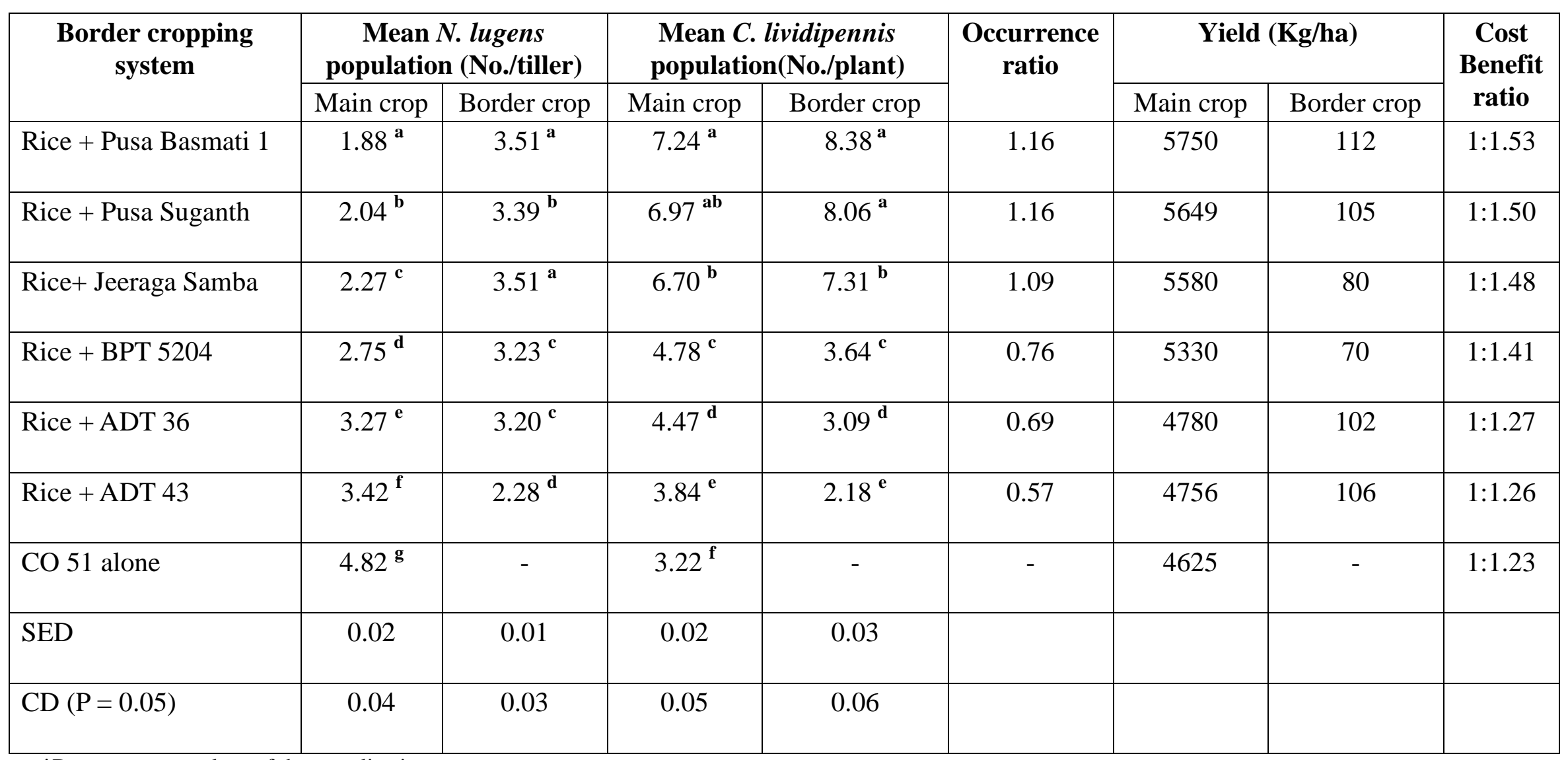

*Data are mean values of three replications

Figures were transformed by square root transformation and the original values are given

In a columns means followed by same letter(s) are not significantly different $(\mathrm{P}=0.05)$ by DMRT 
Table.3 Behavioral bioassay of Cyrtorhinus lividipennis against leaf samples of different border crop in olfactometer

\begin{tabular}{|c|c|c|c|c|c|}
\hline \multirow[t]{2}{*}{ Treatments } & \multicolumn{5}{|c|}{ No. of $C$. lividipennis (no./arm)* } \\
\hline & 5 MAR & 10 MAR & 15 MAR & 20 MAR & MEAN \\
\hline Pusa Basmati-1 & $2.00^{\mathrm{a}}$ & $3.00^{\mathrm{a}}$ & $3.50^{\mathrm{a}}$ & $3.50^{\mathrm{b}}$ & $3.00^{\mathrm{a}}$ \\
\hline Pusa Suganth & $1.75^{b}$ & $3.00^{\mathrm{a}}$ & $3.50^{\mathrm{a}}$ & $4.00^{\mathrm{a}}$ & $3.06^{\mathrm{a}}$ \\
\hline Jeeraga Samba & $1.75^{b}$ & $2.25^{b}$ & $2.50^{b}$ & $3.50^{b}$ & $2.50^{b}$ \\
\hline BPT 5204 & $1.00^{\mathrm{c}}$ & $1.25^{\mathrm{c}}$ & $2.00^{\mathrm{c}}$ & $2.25^{\mathrm{c}}$ & $1.63^{\mathrm{c}}$ \\
\hline ADT 36 & $0.50^{\mathrm{d}}$ & $1.00^{\mathrm{d}}$ & $1.00^{\mathrm{e}}$ & $1.00^{\mathrm{e}}$ & $0.88^{\mathbf{e}}$ \\
\hline ADT 43 & $1.00^{\mathrm{c}}$ & $1.00^{d}$ & $1.50^{\mathrm{d}}$ & $1.75^{d}$ & $1.31^{\mathrm{d}}$ \\
\hline $\mathrm{CO} 51$ & $0.25^{\mathrm{e}}$ & $0.50^{\mathrm{e}}$ & $0.75^{\mathrm{f}}$ & $0.75^{f}$ & $0.56^{\mathrm{f}}$ \\
\hline S.Ed & 0.01 & 0.01 & 0.01 & 0.01 & 0.01 \\
\hline $\mathrm{CD}(0.05 \%)$ & 0.01 & 0.02 & 0.02 & 0.02 & 0.02 \\
\hline
\end{tabular}

*Mean of 4 replications

** MAR Minutes After Release

Figures were transformed by square root transformation and the original values are given

In a columns means followed by same letter(s) are not significantly different $(\mathrm{P}=0.05)$ by DMRT

Table.4 Behavioral bioassay of Cyrtorhinus lividipennis against flower samples of different border crop in olfactometer

\begin{tabular}{|l|c|c|c|c|c|}
\hline \multirow{2}{*}{ Treatments } & \multicolumn{5}{|c|}{ No. of C. lividipennis (no./arm)* } \\
\cline { 2 - 6 } & $\mathbf{5 ~ M A R ~}^{*}$ & $\mathbf{1 0 ~ M A R ~}^{\mathbf{*}}$ & $\mathbf{1 5} \mathbf{M A R}$ & $\mathbf{2 0}$ MAR & MEAN \\
\hline Pusa Basmati-1 & $2.75^{\mathbf{a}}$ & $3.00^{\mathbf{a}}$ & $3.75^{\mathbf{b}}$ & $4.75^{\mathbf{a}}$ & $3.56^{\mathbf{a}}$ \\
\hline Pusa Suganth & $2.50^{\mathbf{b}}$ & $3.00^{\mathbf{a}}$ & $4.00^{\mathbf{a}}$ & $4.50^{\mathbf{b}}$ & $3.50^{\mathbf{a}}$ \\
\hline Jeeraga Samba $^{\mathbf{b}}$ & $2.50^{\mathbf{b}}$ & $2.50^{\mathbf{b}}$ & $3.25^{\mathbf{c}}$ & $3.25^{\mathbf{c}}$ & $2.88^{\mathbf{b}}$ \\
\hline BPT 5204 & $1.25^{\mathbf{c}}$ & $1.50^{\mathbf{c}}$ & $2.00^{\mathbf{d}}$ & $2.75^{\mathbf{d}}$ & $1.88^{\mathbf{c}}$ \\
\hline ADT 36 & $0.00^{\mathbf{e}}$ & $0.75^{\mathbf{e}}$ & $1.25^{\mathbf{e}}$ & $2.00^{\mathbf{e}}$ & $1.00^{\mathbf{e}}$ \\
\hline ADT 43 & $0.50^{\mathbf{d}}$ & $1.25^{\mathbf{d}}$ & $1.25^{\mathbf{e}}$ & $1.25^{\mathbf{f}}$ & $1.06^{\mathbf{d}}$ \\
\hline CO 51 & $0.00^{\mathbf{e}}$ & $0.75^{\mathbf{e}}$ & $1.00^{\mathbf{f}}$ & $0.50^{\mathbf{g}}$ & $0.56^{\mathbf{f}}$ \\
\hline S.Ed & 0.01 & 0.01 & 0.01 & 0.01 & 0.01 \\
\hline CD $(0.05 \%)$ & 0.02 & 0.02 & 0.02 & 0.02 & 0.02 \\
\hline
\end{tabular}

*Mean of 4 replications

** MAR Minutes After Release

Figures were transformed by square root transformation and the original values are given In a columns means followed by same letter(s) are not significantly different $(\mathrm{P}=0.05)$ by DMRT

Aromatic plants significantly reduced pest abundance compared with natural grasses or clean tillage, especially the number of dominant pests that harm. It is speculated that these results were mainly caused by the repellent effects of aromatic plants. Aromatic plants contain a variety of volatile oils and aromatic properties that may interfere with the ability of a herbivore to locate a host, feed, migrate and breed, and thus prevent herbivore infestation (Lu et al., 2007; Uvah and Coaker 1984; Stan et al., 2003).

The yield of rice crop was higher in rice + Pusa Basmati-1 border cropping system (5750 $\mathrm{kg} / \mathrm{ha}$ ) followed by rice + Pusa Suganth (5649 $\mathrm{kg} / \mathrm{ha})$ and rice + Jeeraga Samba $(5580 \mathrm{~kg} / \mathrm{ha})$. The remaining border cropping systems had 
minimal yield. Rice alone without border cropping system recorded the lowest yield $(4625 \mathrm{~kg} / \mathrm{ha})$. The variation in yield may be due to the border cropping system. In border cropping system, the population of natural enemies was higher compared to pure rice crop.

As the population of natural enemies was higher in border cropping system, the pest population was decreased and yield variation may occur. The increase in yield of rice crop as well the yields of border crops had impact on $\mathrm{C}$ : $\mathrm{B}$ ratio, which recorded $1: 1.53$ and 1:1.50 for border cropped with Pusa Basmati1, Pusa Suganth system respectively.

\section{Olfactometer studies}

\section{Leaf sample}

There was significant difference in the attraction of mirid beetle in olfactometer arms due to different leaf and flower samples of border crop. In Olfactometer studies, mirid bug attraction was very high at 5 MAR in Pusa Basmati-1 leaf sample (2.00) followed by Pusa Suganth leaf (1.75). During 10 MAR the attraction of mirid bug population was very high in Pusa Basmati-1 leaf sample (3.00) followed by Pusa Suganth (3.00). Controls had the lowest population (0.50). At 15 and 20 MAR, the mirid bug attraction was high in Pusa Suganth leaf $(3.50,4.00)$ followed by Pusa Basmati leaf sample (3.50, $3.50)$.

At the same time, the controls recorded lowest population $(0.75,0.75)$. The overall mean population was highly significant in Pusa Suganth leaf sample (3.06) followed by Pusa Basmati (3.00), Jeeraga Samba (2.50) and BPT 5204 leaves (1.63). All the treatments registered significant attraction than in control and each recorded the lowest predator attraction of 0.56 (Table 3 ).

\section{Flower sample}

Flower samples from the border crops were collected and kept in Olfactometer arms. Number of mirid bugs attracted towards various flower samples is given in Table 4. At 5 MAR, the mirid bug attraction was high in Pusa Basmati-1 (2.75), followed by Pusa Suganth (2.50) and the lowest population was recorded in BPT 5204 flowers (0.00).

During 10 MAR, the attraction of mirid bugs was towards Pusa Basmati 1 (3.00) and Pusa Suganth (3.00). At $15 \mathrm{MAR}$, the attraction was more in Pusa Suganth (4.00) and Pusa Basmati-1 (3.75) and less in control (1.00).

At 20 MAR, the attraction was more in Pusa Basmati (4.75) and Pusa Suganth (4.50). The overall mean attraction was recorded high in Pusa Basmati 1 (3.56) followed by Pusa Suganth (3.50), Jeeraga Samba (2.88), BPT 5204 (1.88), ADT 43 (1.06) and ADT 43 (1.00).

These findings are supported by Ballal and Singh (1999), who reported that both sexes of $C$. carnea have a significantly higher orientation preference for sunflower. Zhu et al., (2013) reported that, Sesamum indicum, Emilia sonchifolia, and Impatiens balsamena appeared potentially suitable for supporting Anagrus optabilis and Anagrus nilaparvatae to the extent that adults were attracted to the odours of these flowers.

From the above results, Pusa Basmati-1 and Pusa Suganth could be recommended for creating flowering strips in the border of rice crop. It will increase the predator, $C$. lividipennis which leads to the suppression of rice planthopper infestation in rice main crop. The aroma and non-aroma rice varieties can be sown in the appropriate time to make available the alternate food sources to natural enemies throughout the crop season. 


\section{Acknowledgement}

The authors thankfully acknowledge Dr. S. Robin, Professor, Plant Breeding and Genetics, Professor and Head, Department of Rice, TNAU, Coimbatore for providing seed materials and helping in conduct of the experiments.

\section{References}

Akila, S. and Sundara Babu, P.C. 1994. Release of different doses of Trichogramma and its effect on internode borer, yield and quality of sugarcane. Sugarcane London. 2: 22-23.

Altieri, M.A., and Schmidt, L.L. 1986. Cover crop manipulation in Northern California orchards and vineyards: effects on arthropod communities. Biol. Agric. Hortic., 3: 1-24.

Ballal, C.R. and Singh, S.P. 1999, Host plant mediated orientation and ovipositional behavior of three species of chrysopids (Neuroptera: Chrysopidae). Biol. Control., 16: 47-53.

Eilenberg, J., Hajek, A. and Lomer, C. 2001. Suggestions for unifying the terminology in biological control. Biol. Control., 46: 387-400.

Gomez, K.A. and Gomez, A.A. 1984. Statistical procedures for Agricultural Research. John Wiley and Sons, New Delhi. 680 p.

Gurr, G.M., Scarratt, S.L., Wratten, S.D., Berndt, L. and Irvin, N. 2004a. Ecological engineering, habitat manipulation and pest management. In Ecological engineering for pest management: advances in habitat manipulation for arthropods, pp. 1-12.

Gurr, G.M., Wratten, S.D. and Altieri, M.A. 2004b. Ecological engineering: advances in habitat manipulation for arthropods. Collingwood (Australia): CSIRO Publishing. 232 p.
Kumar, L., Yogi, M.K. and Jagdish, J. 2013. Habitat manipulation for biological control of insect pests: A review. Research Journal of Agriculture and Forestry Sciences, 2320: 6063.

Lu, W., Hou, M.L., Wen, J.H. and Li, J.W. 2007. Effects of plant volatiles on herbivorous insects. Plant Prot. 33: 711.

Muthukrishnan, N. and Dhanasekaran, V. 2014. Management of cotton pink bollworm Pectinophora gossypiella (Saunders) through trap cropping system. In: Extended Summary book on National Symposium on Emerging Trends in Eco-Friendly Insect Pest Management held at Tamil Nadu Agricultural University, Coimbatore, January 22-24, 2014, A.E. Publications, Coimbatore, pp. 326-32.

Nasiruddin, M. and Roy, R.C. 2012. Rice field insect pests during the rice growing seasons in two areas of hathazari, Chittagong. Bangladesh. J. Zool., 40 (1): 89-100.

Pathak, M.D. 1970. Insect pests of rice and their control. IRRI. (ed.). Rice production manual. Los Baños: University of the Philippines, College of Agriculture in cooperation with the International Rice Research Institute, 171-198.

Sardesai, N., Rajyashri, K.R., Behura, S.K., Nair, S. and Mohan, M. 2001. Genetic, physiological and molecular interactions of rice and its major dipteran pest, gall midge. Plant Cell, Tissue and Organ Culture, 64:115-131.

Stan, F., Helen, B. and Rosemary, H.C. 2003. Companion planting - do aromatic plants disrupt host-plant finding by the cabbage root fly and the onion fly more effectively than non-aromatic plants. Entomol Exp Appl, 109:183-195.

Thies, C. and Tscharntke, T. 1999. Landscape structure and biological control in 
agroecosystems. Science, 285: 893-895.

Uetz, G.W. 1991. Habitat structure and spider foraging. In: Bell, S.S., McCoy, E.D. and Mushinsky, H.R. editors. Habitat structure: the physical arrangement of objects in space. Population and Community Ecology Series. Netherlands: Springer. pp 325-348.

Uvah, III and Coaker, T.H. 1984. Effect of mixed cropping on some insect pests of carrots and onions. Entomol Exp Appl., 36: 159-167.

Zhu, P., Gurr, G.M., Lu, Z., Heong, K.L., Chen, G., Zheng, X. and Yang, Y. 2013. Laboratory screening supports the selection of sesame (Sesamum indicum) to enhance Anagrus spp. parasitoids (Hymenoptera: Mymaridae) of rice planthoppers. Biological Control, 64(1): 83-89.

\section{How to cite this article:}

Chandrasekar, K., N. Muthukrishnan and Soundararajan, R.P. 2017. Ecological Engineering Cropping Methods for Enhancing Predator, Cyrtorhinus lividipennis (Reuter) and Suppression of Planthopper, Nilaparvata lugens (Stal) in Rice- Effect of Border Cropping Systems. Int.J.Curr.Microbiol.App.Sci. 6(12): 330-338. doi: https://doi.org/10.20546/ijcmas.2017.612.039 